\title{
VIDEO INDÍGENA Y ANTROPOLOGÍA COMPARTIDA: UNA EXPERIENCIA COLABORATIVA CON VIDEASTAS MAYA-Q'EQCHI' DE GUATEMALA
}

\author{
Carlos Y. Flores
}

$\mathrm{E}$ ste artículo toma en cuenta el papel del video indígena y la antropología compartida entre comunidades maya-q'eqchi' de Alta Verapaz, Guatemala. ${ }^{1}$ El presente documento analiza las condiciones subjetivas e históricas que sirvieron de contexto para una producción colaborativa entre videastas locales, sus comunidades y mi propia práctica como antropólogo visual, también evalúa algunas de las implicaciones que todo este experimento tuvo entre los participantes. Se apunta que este proyecto llevado a cabo en la comunidad no sólo generó importantes herramientas metodológicas, también nuevos mecanismos para la reconstrucción cultural y social de las comunidades involucradas tras el traumático y violento periodo de guerra civil que les tocó vivir. En este contexto, la producción de videos ofreció un espacio al interior de la práctica más amplia de antropología compartida donde cada participante pudo alcanzar sus propias metas a través de procesos y productos híbridos. Por lo tanto, este proyecto representó una oportunidad para explorar formas en las que la antropología y el video etnográfico pueden ser al mismo tiempo útiles tanto para el investigador como para las comunidades implicadas. Sin embargo,

Carlos Y. Flores, Departamento de Antropología, Universidad Autónoma del Estado de Morelos, UAEM. el ejercicio también mostró las contradicciones y complejidades de dicha práctica antropológica en colaboración o "compartida”.

\section{Antropología en un hogar en conflicto}

Fui a la región q'eqchi' de Alta Verapaz, Guatemala, con el fin de desarrollar mi investigación de doctorado en la segunda mitad del decenio de 1990. Este proyecto buscaba evaluar los usos, posibilidades e impactos de los medios de comunicación electrónicos entre los grupos indígenas del país desde una perspectiva antropológica. Sin embargo, mi interés no sólo era académico. Durante mi periodo de campo, el país estaba emergiendo de uno de los conflictos armados más largos y violentos de Latinoamérica, ${ }^{2}$ el impacto político de la cuestión indígena en el ámbito nacional e internacional se incrementaba día con día. Ubicados en las entonces llamadas “áreas de conflicto”, los q’eqchi” del departamento de Alta Verapaz, grupo maya con cerca de 361000 miembros, habían sufrido intensamente el conflicto y se encontraban superando la violencia del pasado. En tal contexto, pensaba que el material obtenido a través de un proyecto de video comunitario daría no sólo información etnográfica importante sobre un grupo indígena y sus transformaciones recientes, sino potencialmente 
también nuevos mecanismos para la reconstrucción cultural y terapia colectiva tras el agudo proceso de dislocación social y militarización.

Con anterioridad había leído trabajos de antropólogos sobre otras experiencias de uso de medios de comunicación indígena en Brasil, Canadá, Estados Unidos y Australia, así esperaba participar o ayudar a desarrollar algo similar en Guatemala. Sin embargo, algunos aspectos característicos del país se distanciaban de los otros ejercicios de video comunitario. A diferencia de los kayapó de Brasil o de los aborígenes australianos, los indígenas guatemaltecos no eran un grupo cultural minoritario, ni tampoco tenían ningún tipo de autonomía territorial para proteger y preservar su etnicidad y forma de vida particular. Por el contrario, con alrededor de seis millones de personas, los pueblos indígenas de Guatemala constituyen cerca de la mitad de la población y se encontraban completamente integrados al sistema socioeconómico del país, aunque de manera muy desventajosa. De hecho, dichos pueblos indígenas hasta entonces habían sido esenciales para mantener y reproducir el arcaico modelo agroexportador, controlado por una élite no indígena y semifeudal. Otra diferencia importante era el conflicto armado en sí, el cual había dejado una profunda huella en la identidad y cultura de los grupos indígenas del país.

A pesar de mis orígenes guatemaltecos no indígenas, un ladino compartía una historia de conflicto con los mayas con quienes quería trabajar. Trece años atrás había abandonado Guatemala debido a la violencia política, llegando a México donde inicié mis estudios en antropología, que después continuaría en Inglaterra. Este nuevo proyecto, entonces, para mí representaba una oportunidad de reencuentro con un pasado problemático e irresuelto. Una vez de regreso a Guatemala, el estudiar la identidad e historia de los q'eqchi' con el tiempo reveló muchos aspectos de mi propia identidad. Las narrativas en las comunidades acerca de eventos traumáticos del pasado me ayudaron a reconstruir mi propia narrativa como guatemalteco nuevamente en mi propio país. Esta situación personal tan peculiar me hizo entender aún más lo que James Clifford afirma: “cada versión de un 'otro' donde quiera que se encuentre, también es la construcción de un 'yo' cuando se elaboran los textos etnográficos" (Clifford y Marcus, 1986: 23). De tiempo en tiempo, por lo tanto, miraba a la sociedad guatemalteca desde la confusa perspectiva como ciudadano y como extranjero - paradójicamente, tantos años en el exterior también me habían configurado de alguna forma "más guatemalteco".

Claramente, esta mitad guatemalteca tiñó mi empresa antropológica ya que me colocó en una posición peculiar de distancia y cercanía con la sociedad con la que estaba trabajando. Sin embargo, aunque las contradicciones eran muchas, básicamente por mi origen ladino guatemalteco de clase media urbana ahora viviendo en otra sociedad, el proceso histórico de estas comunidades estaba tan entretejido con el mío, que encontré difícil tratar de separar nuestros mundos de la forma en que lo hace una antropología más tradicional basada en la alteridad. Por lo mismo, para mí el trabajo de campo más bien representó una oportunidad de "probar y explorar formas en las que nuestras experiencias nos unen o conectan con los otros, en vez de separarnos" (Michael Jackson, citado en Stoller, 1992: 214). Debido a todo lo anterior mi deseo se fincó en desarrollar una práctica antropológica entre los q'eqchi' desde una perspectiva más personal y horizontal encuadrada en experiencias compartidas.

Afortunadamente, algunos desarrollos revisionistas recientes en la disciplina ayudaron a implementar mi objetivo metodológico. La preocupación contemporánea de entender las relaciones que se establecen entre antropólogos y sujetos de estudio daba nuevos paradigmas donde la voz única del investigador estaba siendo cuestionada cuando las voces de los sujetos empezaban a ser escuchadas al interior de la 
comunidad académica. En este proceso, la antropología había acelerado su transición de un enfoque "objetivo" y positivista — dirigido básicamente a "representar" al "otro" cultural— hacia una perspectiva más subjetiva donde la voz del autor empezaba a ser considerada como de naturaleza más personal. Tales enfoques, recientemente promulgados por corrientes posmodernistas, suponían la inclusión de múltiples voces subjetivas que tenían un valor por sí mismas, independientemente de la interpretación del autor. Según Adam Kuper (1986: 542), durante estas revisiones metodológicas "había que darles a los nativos una voz completa. Esta posición se justificó con un argumento político en contra de la dominación y a favor de la expresión democrática". Los comentados movimientos críticos habían llevado a un mayor involucramiento de los antropólogos con sus sujetos de estudio, aunque sucedía en niveles y formas diferentes. Como lo menciona George A. Marcus:

...otras experiencias culturales pueden ser evocadas $\mathrm{O}$ representadas por un cambio fundamental en la forma en que pensamos acerca de la construcción de los textos etnográficos. Los intercambios dialógicos entre el etnógrafo y el otro, el compartir la autoridad textual con los mismos sujetos, el recuento autobiográfico como la única forma apropiada para fusionar la experiencia cultural del otro con la del etnógrafo — todos estos son intentos para cambiar radicalmente la forma en que se ha constituido la etnografía convencional con el fin de transmitir auténticamente otras experiencias culturales (1986:168).

Sin duda, estos enfoques teóricos me ofrecieron herramientas metodológicas básicas para desplegar mi propia práctica antropológica en mi país, en el sentido de que ayudaron a situarme como autor, al interior de mi situación subjetiva como antropólogo "nativo" con la gente con la que estaba trabajando. También conllevaban la promesa de una interacción más compartida y horizontal con el universo conceptual de los sujetos de estudio. Sin embargo, estas corrientes de pensamiento no respondían a una pregunta fundamental y práctica que todavía quedaba por resolver: si la etnografía cada vez más se ha vuelto un diálogo entre múltiples voces, ¿por qué al final sólo uno de los participantes normalmente se beneficia de la práctica antropológica? En otras palabras, aunque la producción de textos antropológicos y ultimadamente el conocimiento estaba empezando a ser alcanzado de una forma más interactiva y "colectiva”, todavía estaba el problema del consumo/apropiación etnográfica, una área apenas mencionada en este debate revisionista. Las teorías antropológicas, con todo su nuevo y sofisticado entramado para "dar una voz a los nativos", parecían en gran medida seguir preocupadas de asuntos relacionados con la "traducción cultural" para los grupos dominantes. ${ }^{3}$

Muchas de mis carencias metodológicas, sin embargo, pudieron resolverse al buscar en otras ramas de la disciplina relacionadas con sus usos prácticos, notablemente en las áreas de antropología aplicada y política. Quienes las promulgaban con frecuencia utilizaban el conocimiento obtenido en el campo para implementar políticas y proyectos desarrollistas. La tendencia de tales experiencias, sin embargo, era la de facilitar la promoción de cambios culturales y sociales en individuos, comunidades y sociedades, lo que con frecuencia se asociaba con una modernización y cambio político de corte capitalista. En ese sentido e independientemente de los resultados, tales prácticas no me parecían tan atractivas ya que con frecuencia se aplicaban sin importar la opinión de las comunidades. Incluso cuando la gente en el campo se involucraba en tales proyectos de forma más participativa, obviamente resultaba muy difícil para ellos escapar de la lógica económica y política impuesta por los donantes nacionales y extranjeros que se encontraban financiando dichos programas. 
En ese sentido, antes del fin del conflicto armado guatemalteco en diciembre de 1996, varias ONG locales e internacionales empezaron a organizar múltiples iniciativas desarrollistas a lo largo del país alrededor del proceso de paz. Éstas se agregaban a otras ya existentes - aunque escasas — desde décadas atrás en campos como el de la salud, la educación a distancia y en menor medida el medio ambiente, que habían logrado mantener su presencia en parte no sólo por el apoyo prestado por instituciones tales como las iglesias católica y protestante ${ }^{4}$ y fundaciones privadas, sino también porque políticamente no fueron percibidas como una amenaza directa al statu quo.

Ahora los movimientos desarrollistas de mediados de la década de 1990, sin embargo, respondían no sólo a los eventos nacionales sino a poderosas tendencias internacionales, particularmente ideas neoliberales de transferir las responsabilidades y decisiones gubernamentales a la "sociedad civil". Además de este proceso globalizador, la comunidad internacional también tenía un interés geopolítico en ayudar a finalizar el conflicto bélico en Guatemala —único conflicto armado que quedaba en Centroamérica a mediados la década de 1990 - . Al proveer ayuda financiera y política, el mundo industrializado estaba apoyando los esfuerzos regionales para superar la inestabilidad política y promover el desarrollo económico con el objetivo de enfrentar el legado de las guerras civiles. ${ }^{5}$ En este contexto la ayuda internacional se canalizaba no sólo a través del gobierno, sino de ONG y organizaciones de base con el fin de incrementar la participación popular en los procesos de reconstrucción y desarrollo nacional.

Fue en uno de estos proyectos desarrollistas en la región q’eqchi' donde logré articular mi propuesta antropológica, dándome la oportunidad de combinar críticamente los parámetros metodológicos de las perspectivas posmodernas, particularmente en relación con su dimensión multivocal, con otros de la antropología aplicada. Durante una corta visita a la región, previa a mi trabajo de campo, supe que había un equipo de videastas q'eqchi' trabajando con la Orden Benedictina de la iglesia católica en la ciudad de Cobán. Una de las ideas principales detrás de dicho proyecto de video comunitario había sido la de enseñar a miembros de la comunidad cómo producir materiales en video en su propio idioma y por ellos mismos, centrándose en las áreas de salud, religión y educación. De hecho, el proyecto era la continuación de la exitosa experiencia de Radio Tezulutlán, la radio católica local, también establecida por el padre Bernardino que había estado transmitiendo en q'eqchi' desde el decenio de 1970. 6 A través de ambas formas electrónicas de comunicación, la iglesia esperaba superar ciertas barreras para su trabajo originadas por el monolingüismo y los altos grados de analfabetismo en la región. A mediados de la década de 1990, el proyecto tenía el apoyo de la AID y del Fondo Nacional para la Paz, FONAPAz, organismo estatal que se encontraba canalizando la ayuda externa para los proyectos relacionados con el proceso de paz. Con esta información a la mano, fui a visitar a los participantes en el proyecto y les hablé acerca de mi interés académico. Después de nuestra plática me aceptaron en el grupo, lo que dio inicio a una relación de colaboración entre los videastas locales y mi persona, el antropólogo.

Tras abrirse esta posibilidad, empecé sistemáticamente a recolectar información acerca de otros proyectos de comunicación alternativa entre sectores indígenas y populares donde habían estado involucrados desde 1960 investigadores sociales, activistas, ONG, grupos religiosos y hasta organismos estatales en su concepción y desarrollo. América latina había sido un campo fértil para ello, y así se implementaron proyectos de comunicación popular alternativa que pretendían abrirse paso ante el cerco informativo impuesto por las grandes cadenas hegemónicas de comunicación privada y comercial, las que, en general, buscaban hacer llegar mensajes religiosos, desarrollistas, integracionistas y hasta 
contestatarios en países con regímenes autoritarios o dictaduras militares en los años de 1960 a 1980. Así, por ejemplo, hubo en el caso de la diócesis de Verapaz en Guatemala, un uso importante de la radio y de audiocasetes por parte de la iglesia católica en todo el continente, con iniciativas como la pionera Radio Sutatenza que empezó en 1947, a transmitir programas educativos y religiosos en Colombia; o Radio Diócesis, en Chiapas, México, un par de décadas después. Estas emisoras junto a otras similares, que transmitían mensajes a grupos campesinos y marginales, llegaron a constituir a finales de la década de 1960, más de 500 radio escuelas en todo el continente, que en su mayoría se unieron, con la organización católica, a la Asociación Latinoamericana de Educación Radiofónica, ALER, en $1972{ }^{7}$

Por otro lado, en un terreno más secular y militante, se contaba con varias experiencias como la de los radioforos agrarios de la Radio Nacional/FUDECO y el Cine Urgente en Venezuela (Capriles, 1981: 156); el casete-foro de "doble vía" entre cooperativas de pequeños campesinos en Uruguay (Kaplún, 1981: 215-216); la imprensa nanica, "prensa enana", en Brasil, donde grupos sindicales, intelectuales y humoristas reaccionaron al golpe militar de 1964 con publicaciones alternativas y contestatarias como O Pasquim, El Centavo o el Manequim, que en conjunto llegaron a tener tiradas de hasta medio millón de ejemplares y que fueron duramente reprimidas en el decenio de 1970 (Selser, 1981). Asimismo, ya en la década de 1980 no se pueden obviar las experiencias de las guerrilleras Radio Sandino en Nicaragua, del Sistema Radio Venceremos de El Salvador, y de La Voz Popular en Guatemala. En tales contextos, los defensores de los medios de comunicación a pequeña escala estaban experimentando en la práctica, el desarrollo de proyectos alternativos que de alguna forma garantizaban la palabra "a quienes siempre se les ha negado su uso" (Ana María Pepino, citada en Melgoza, 2005: 92).
En el caso del trabajo específico con medios electrónicos de comunicación hacia grupos indígenas, pude enterarme también de importantes iniciativas semi-estatales apoyadas por antropólogos, como el "Proyecto de Video en las Aldeas" que el Centro de Trabajo Indigenista ha prestado desde 1987 a indios amazónicos en Brasil "en el contexto de movimientos de reafirmación étnica” (Gallois y Carelli, 1995: 49), o el del Instituto Nacional Indigenista de México referido al Proyecto de Transferencia de Medios Audiovisuales a Comunidades y Organizaciones Indígenas, que en la década de 1990 derivó en los Centros de Vídeo Indígena en distintos estados del país (Gómez Mont, 2002). Tales programas alternativos a las grandes cadenas comerciales de información y entretenimiento audiovisual se habían venido desarrollando asimismo en contextos fuera de Latinoamérica, en lugares tan distantes y diferentes como entre los inuit de Canadá, los pequeños artesanos en la India o entre los aborígenes australianos. Algunos investigadores interesados en estos fenómenos los describieron, de forma un tanto entusiasta, como "nuevos vehículos de comunicación interna y externa, de preservación cultural y lingüística, de autodeterminación y de resistencia a la dominación cultural externa" (Ginsburg, 1997: 119). ${ }^{8}$

Sin embargo, de todas estas iniciativas, hubo una que en particular me impresionó, ya que se acomodaba bastante bien con las ideas que ya iba desarrollando acerca de mi posible participación como antropólogo y comunicador en la comunidad indígena donde pensaba trabajar. Tal descubrimiento fue el trabajo pionero del cineasta francés Jean Rouch y sus ideas de "antropología compartida", término acuñado en la década de 1960 después de que éste lograra el involucramiento activo de miembros de comunidades africanas en la producción de sus películas. Según Paul Stoller, Rouch desarrolló dicho enfoque antropológico mientras presentaba sus películas a las mismas comunidades que previamente había filmado: 
Miembros de la audiencia le pidieron a Rouch mostrar el filme una y otra vez -lo proyectó cinco veces esa noche. Como a la medianoche, la gente empezó a hacer comentarios sobre el filme. Era la primera vez que los songhay habían criticado su trabajo. Le decían que su película no era buena; necesitaba más hipopótamos y menos música. Rouch les pidió explicaciones. Él había añadido una tonada tradicional, un gowey-gowey, para dramatizar la cacería, pero la gente le explicó que cazar un hipopótamo requería silencio -el ruido ahuyentaría a los hipopótamos (...) Esa noche, Rouch y la gente de Ayoru fueron testigos del nacimiento del 'cine participativo' en África, y la etnografía se volvió, para Rouch, una empresa compartida. Finalmente eliminó la música de la pista de audio del filme Bataille sur le grand fleuve (1992: 43).

\section{Estableciendo las bases para una experiencia de video colaborativo}

En un lento y a veces difícil proceso de integración con el equipo q'eqchi' de video, adopté al principio el método antropológico clásico de "observación participante" durante las prácticas que tenían en la ciudad de Cobán y cuando filmaban en las aldeas. Básicamente, esto era seguir a los videastas indígenas y observarlos interactuar entre ellos y con otros miembros de sus comunidades, desarrollar una buena relación, pedirles explicaciones cuando fuera posible sobre sus actividades, y después escribir todo lo que pudiera en mi diario de campo. Durante este proceso, a los q'eqchi' no parecía importarles que yo estuviera, aunque indudablemente se comportaban más reservados cuando yo me encontraba presente.

En este periodo inicial, me llamaron la atención tres situaciones, debido a que de alguna manera chocaban con mis expectativas sobre el video indígena, según mis lecturas anteriores. La primera era que mientras filmaban, el equipo prestaba poca atención a lo que mucha de la literatura antropológica sobre la región refiere como prácticas mayas "esenciales", tales como las ceremonias relacionadas con semillas "sagradas": maíz y frijol; los rituales alrededor de ciclos de vida; las mitologías o las referencias a Truultaq'a, la montaña sagrada, uno de los símbolos locales más importantes. Por el contrario, los videastas se concentraban más bien en aplicar un enfoque estrictamente desarrollista, filmando y presentando temas como prácticas higiénicas, el uso de pesticidas, la construcción de letrinas, el trabajo en las cooperativas, etc. Cuando filmaban ceremonias religiosas, normalmente las asociaban con festividades católicas y no "mayas". En segundo lugar, a pesar de que varios de los jóvenes participantes habían estado enrolados en el ejército, objetos de origen militar se podían ver por todas partes en sus comunidades: botas, camisetas militares, fotos mientras prestaban servicio militar, etc.; nadie parecía interesado en filmar los eventos relacionados con la guerra civil o sobre la situación política en general. Y en tercer lugar, los videos finales se hacían en español, un idioma que apenas entendía la mayoría de los q'eqchi', quienes supuestamente eran su principal público. Más tarde entendí que esta visión hacia fuera en vez de hacia dentro de sus comunidades, estaba vinculada a los procesos en marcha de integración nacional en el posconflicto y a los esfuerzos del Estado, todavía militarizado, por ampliar el consenso y legitimidad social a través de la canalización de fondos internacionales a proyectos de este tipo.

Después de algunas semanas entre el equipo de videastas q'eqchi' me empecé a sentir incómodo, pues era el único que no tenía un papel claro durante las sesiones de capacitación, filmación y edición. El equipo sabía que yo tenía alguna experiencia en producción de documentales para la televisión y esperaba que me involucrara más activamente en el proyecto. De cuando en cuando me pedían que les enseñara lo que yo sabía de televisión. Al principio tenía mis dudas, pues temía que los podía "contaminar" y bloquear el desarrollo de una narrativa filmica particular q'eqchi'. Sin embargo, 
pronto me di cuenta que eso no tenía sentido, ya que este proceso se estaba dando de todas formas, pues los jóvenes estaban expuestos permanentemente a la influencia de la televisión comercial, en donde miraban películas norteamericanas o telenovelas mexicanas, de las cuales tomaban ideas para sus producciones. Tras algunos titubeos iniciales, finalmente decidí colaborar con ellos, en lo que podría llamarse una antropología conscientemente intervencionista. En general, mi participación consistió en transmitirles otras técnicas de producción de video aparte de los conocimientos que ya tenían, por ejemplo, la elaboración de guiones, la iluminación, los acercamientos y detalles, el uso de más de una cámara para el mismo evento, las técnicas de entrevista, entre otros.

Sintiéndome más seguro dentro del grupo y siguiendo mi instinto antropológico, después les propuse experimentar con nuevas narrativas filmicas y con una reorientación de sus temas de interés, para con ello producir en sus comunidades documentales en su propio idioma y sobre temas más "tradicionales" o "ancestrales" mayas. El impacto del proceso de modernización y la guerra civil habían estado erosionando rápidamente tales prácticas y les sugerí que guardar un registro visual de esto sería una contribución importante para el patrimonio de las generaciones futuras. A los jóvenes videastas les llevó un tiempo aceptar tal propuesta, lo que finalmente hicieron tras una serie de deliberaciones y negociaciones. Sin embargo, sus padres y los ancianos de Esperanza Chilatz, la comunidad seleccionada para filmar, se entusiasmaron con el nuevo proyecto y estuvieron dispuestos a colaborar tan pronto oyeron de él. Esta brecha generacional, en buena medida venía de las diferentes expectativas existentes, según la edad y posición al interior de las comunidades lo que, a su vez, era influido por factores externos relacionados con la dinámica nacional y la guerra civil. Ciertamente, durante los últimos quince años tales eventos habían afectado profundamente la naturaleza de la organización comunal interna. ${ }^{9}$

Finalmente y tras largas discusiones acordamos filmar los rituales asociados con la siembra del maíz, debido en parte a que esta actividad no era controversial en términos políticos y también por su importancia socioeconómica y cultural entre las sociedades rurales mayas. Durante la filmación, los ancianos y sus esposas nos ayudaron, sin reserva, de muchas formas e incluso sugirieron "actuar" partes de la actividad frente a la cámara, algo que rechazamos de forma cautelosa. Sin embargo, sus explicaciones sobre este ciclo anual previamente filmadas a través de entrevistas, posteriormente nos dio un marco de referencia ya durante la filmación de los rituales y también estructuró en buena parte la narrativa del documental definitivo. Mientras tanto, los jóvenes de la comunidad que estaban participando en el proyecto de video constantemente cambiaban papeles y a veces eran videastas y otras eran parte de la ceremonia de siembra del maíz, diluyendo con esto las fronteras entre filmar el ritual o ser parte activa de él. Estos papeles cambiantes, junto a la presencia de personas externas dentro del equipo de video —además de quien suscribe había otros dos estudiantes universitarios del país-, estimuló el desarrollo de un puente único, íntimo y revelador del comentado ritual anual y de las diferentes reacciones de los diversos miembros de la comunidad. ${ }^{10}$

\section{Tras una narrativa compartida}

Después de varios meses de filmación intermitente teníamos suficiente material para empezar la edición. Sin embargo, tras algunos días de comenzado este trabajo noté que el interés del equipo q'eqchi' en el proyecto declinó marcadamente. Ciertamente, largas horas de traducción y clasificación del material tenían agotado a todo el mundo al terminar cada jornada, pero el proceso de filmación también había sido una 
actividad muy demandante que sin embargo, logró mantener el entusiasmo de los jóvenes videastas. Con el tiempo, se hizo cada vez más claro que estábamos trabajando bajo diferentes lógicas y expectativas.

Como se fue haciendo evidente, para el equipo de video q'eqchi' el producir un filme tenía más que ver con el proceso, que con el producto en sí. ${ }^{11}$ En la vida comunal maya, los roles sociales, el prestigio y el poder se adquieren a través de acciones individuales y colectivas que son percibidas por la comunidad como servicios. Aunque existen varios servicios individuales "invisibles" como oraciones y ofrendas, mayehak, que se entienden culturalmente como benéficos para el resto de los miembros de la comunidad, en general, la forma más obvia de proyectar la conducta social es a través de actos públicos y tangibles. En este sentido, todo el proyecto de video en Esperanza Chilatz tenía una importante dimensión de acto público y de servicio comunal. Los jóvenes videastas ya habían adquirido considerable estatus y liderazgo en la comunidad a través de su monopolio de conocimientos en video y de su manejo más amplio de temas desarrollistas en los campos de educación y salud. Esta posición social se reforzaba aún más por sus conexiones con instituciones externas poderosas como el ejército y la iglesia católica y sus agendas modernizantes. En este contexto, su capacidad de mediar con instituciones externas y la comunidad provenía más de sus capacidades fílmicas que de sus películas finales. ${ }^{12}$

Sin embargo, otro factor que pudo haber contribuido a que el entusiasmo decayera durante la edición del documental fue mi presencia. Durante la filmación en Esperanza Chilatz mi actividad fue mínima, dado mi limitado entendimiento de las prácticas culturales locales y de mi poca capacidad para interactuar con otros miembros de la comunidad, debido básicamente a un pobre manejo del idioma q’eqchi'. En tales condiciones los videastas indígenas tenían un control total de su espacio social y por lo tanto fueron ellos quienes escogieron la mayoría de las tomas y las personas para entrevistar, mientras que yo sólo les di algún apoyo técnico y sugerí algunas preguntas para las entrevistas. Sin embargo, de regreso en la ciudad, espacio social donde me sentía más cómodo y sobre el cual en muchos sentidos tenía un mejor manejo que ellos, los papeles se invirtieron y empecé a tener una participación más activa en el proceso, mientras que la de ellos declinó. Entre otras cosas, se daba por hecho que yo tenía un conocimiento mayor en producción de video debido a mi experiencia previa en producción de documentales televisivos, también por mi formación académica. Sólo hasta más tarde me di cuenta de que mi relativa seguridad en escribir el guión, en editar y, en general, en saber cómo producir un filme más convencional, pudo haber sido un factor que inhibió al resto del grupo, pese a que yo tenía la intención de incluir la mayor cantidad posible de sugerencias.

En esta fase, se estaban manifestado claramente las ideas modernizantes con las que los jóvenes videastas estaban acostumbrados a estructurar sus producciones. Por lo que pude ver cuando trabajaban sin mi influencia, ellos normalmente recurrían a una narrativa filmica más "expositoria", ${ }^{13}$ la cual les facilitaba llegar a la audiencia directamente, ya fuera por medio de un comentarista a cuadro o con una explicación en la pista de audio, con el fin de demostrar cómo se debían hacer ciertas cosas al interior de la comunidad, como el uso de fertilizantes o la higiene personal, mientras que, apenas prestaban atención a los roles individuales o a las diferentes formas de hacer las cosas. En cierta medida, pienso que esto reflejaba el estilo vertical de transmitir la información, utilizado no sólo por la iglesia católica y los militares, sino por el sistema educativo nacional. En la mayoría de sus producciones, entonces, parecía existir la constante necesidad de una voz con autoridad condicionando la narrativa general. En el caso del proyecto sobre la siembra del maíz, la voz de los ancianos, especialistas del tema, de alguna manera 
coincidió con este esquema general de producir videos con un grado de autoridad. Por lo anterior, los jóvenes videastas al parecer, se sintieron incómodos con el estilo semi-observacional ${ }^{4}$ que yo estaba tratando de introducir al documental. De acuerdo con su experiencia previa, los jóvenes querían al principio agregar música de marimba e incluso hacer comentarios en cada fase de toda la actividad y no apoyarse tanto en las entrevistas a los ancianos. Las discusiones sobre el estilo que debía tener el documental se extendió por unos días. En general, quienes tenían un mayor grado de educación formal se inclinaban más por intentar nuevos estilos o al menos darle el beneficio de la duda a la técnica observacional, mientras que los que tenían menor formación académica preferían mantener el estilo anterior. Finalmente, les propuse que editáramos dos versiones, una de exposición y otra de observación, como forma de romper el impasse, lo cual pareció agradar a todos.

Desafortunadamente, la máquina editora del centro benedictino se descompuso y no había esperanza de que fuera reparada pronto, lo que saboteó la idea de producir dos versiones del documental. Ante esta situación, terminé trabajando la versión final en otro lugar, con los más liberales padres dominicos — varios de ellos también antropólogos- quienes tenían un equipo de edición muy básico. Muy pocos de los jóvenes videastas llegaron a este nuevo lugar; para cuando el filme estaba por concluir ellos prácticamente habían desaparecido. Por lo tanto, edité el filme principalmente con otro joven urbano q'eqchi', Mainor Pacay, que no había participado en la filmación en la comunidad, pero trabajaba permanentemente con los dominicos y también había sido capacitado en producción de videos, dentro del programa que ejercían estos religiosos. Con Mainor, sin embargo, las cosas no fueron fáciles al comenzar nuestro trabajo. Meses atrás habíamos chocado durante un encuentro regular con el equipo de video anterior, donde él abiertamente había cuestionado mi presencia, sugiriendo que yo era un kaxlán, un ladino, y por lo tanto el resto del grupo no debería confiar en mí. Sin embargo, y pese a esta experiencia, tras largas horas de edición en el centro dominico Ak'kután, se mostró cada vez más interesado en aprender sobre la producción de documentales con un estilo observacional y sobre todo el proyecto de recuperación cultural. Durante semanas enteras discutimos las diferentes formas de estructurar el documental y Mainor empezó a confiarme lo que sabía acerca de la cultura q'eqchi', hacía comentarios cuando miraba con detenimiento las secuencias filmadas previamente en Esperanza Chilatz. En consecuencia, mi entendimiento sobre la cultura local se desarrolló enormemente durante ese periodo, mientras que el conocimiento de edición de Mainor también mejoró de manera notable, después de que le transmitiera conocimientos sobre la producción de documentales. Este proceso de aprendizaje de doble vía nos permitió extender puentes de entendimiento y lograr superar muchas de nuestras diferencias iniciales, lo que a la larga se convertiría en una productiva y duradera relación profesional y de amistad. Durante todo este proceso, también visité constantemente al equipo de Esperanza Chilatz pidiéndoles consejos, particularmente cuando surgían dudas acerca de la festividad, tratando de incorporar sus planteamientos en lo posible, al interior de la narrativa "intercultural" del filme. Tras unos meses, el documental Qa Loq Laj Iyaaj, "Nuestra Sagrada Semilla", quedó listo.

En este caminar, me queda claro que tuve la última palabra en el cuarto de edición y por lo tanto mi versión y entendimiento de la ceremonia se mantuvo en la estructura final del material. Éste fue un documento audiovisual etnográfico caracterizado por lo que Clifford llamó un "arreglo jerarquizado de discursos" (1986: 17). ${ }^{15}$ En todo caso, la experiencia terminó formando un estilo de filmación, que tomó prestado del "cine participativo" de Rouch (Stoller, 1992), del 
proyecto de "Video en las Aldeas" de los kayapó en Brasil (Turner, 1991), del "estilo observacional" del Centro Granada de Antropología Visual de Manchester donde yo estudiaba y, por supuesto, del trabajo de cámara y edición de los mismos videastas q'eqchi'. ${ }^{16} \mathrm{Al}$ haber completado tal material, algunas de mis preocupaciones sobre los dilemas generados en relación con la paternidad y destino del documental fueron de alguna manera resueltos. Por ejemplo, mi experiencia me indica que el filme Qa Loq Laj Iyaj es al parecer más digerible para un público q’eqchi’ o maya en general, que para una audiencia académica o no indígena. Esto no sólo se debe al tema en sí, sino también al ritmo y narrativa visual tan particular del documento visual, que en muchas formas se distancia de las películas dominantes que se pueden ver en América Latina, Europa y Norteamérica. Claramente, esta experiencia híbrida hizo posible desarrollar los elementos básicos de un estilo de filmación, que mostró ser bastante aceptado por la población local y también por otros grupos indígenas en el ámbito nacional e internacional. ${ }^{17}$

En resumen, la producción de Qa Loq Laj Iyaaj generó nuevas consideraciones metodológicas, tanto teóricas como prácticas, relacionadas principalmente con asuntos de narrativa, autoría y audiencia. Sin embargo, la práctica demostró que fue muy difícil distinguir claramente entre estos niveles, debido a la naturaleza híbrida del producto final donde los lineamientos convencionales para tales definiciones tienden a desdibujarse. Entonces, en la producción del documental la interdependencia fue tal, que cada participante dejó su marca particular, desde la concepción hasta la cristalización del mismo. Esta práctica, por lo tanto, fue un ejercicio colaborativo, incrustado en una red de relaciones sociales donde diversas referencias culturales e históricas se encontraron, produciendo lo que Marcus y Fisher llamaron "una negociación de significados" (citados en Henley, 1998: 51). ${ }^{18}$

\section{Conclusiones}

Producir videos entre comunidades q'eqchi', en el dinámico contexto de la posguerra guatemalteca, proveyó variadas y ricas avenidas para explorar los límites y posibilidades de proyectos antropológicos aplicados y compartidos. Los filmes Qa Loq Laj Iyaajy Rub'elKurus se produjeron en un ambiente cultural similar, durante el proceso de reconstrucción social, tras un periodo de guerra civil, militarismo y violencia política. Al interior de este contexto, los q'eqchi' se encontraban reforzando nuevamente su identidad étnica y ampliando sus formas de expresión política. Por otro lado, mi agenda como antropólogo tenía claramente diferentes objetivos, que de alguna manera también se lograron satisfacer, pues a través de la interacción con el video tuve acceso privilegiado a información etnográfica que hubiera sido más difícil o imposible de obtener a través de una práctica antropológica tradicionalista.

Desde el principio, la experiencia no era producir el tipo de cine etnográfico que una vez filmado y editado se presentara a una audiencia externa, o sólo a la comunidad particular donde se dieron los eventos registrados. Tampoco fue un proyecto de video indígena como el de los kayapó en Brasil, donde el material final y su narrativa se regularon en última instancia por los mismos productores indígenas, junto con otros miembros de la comunidad. Por el contrario, a través de un enfoque más integral, utilizando un ejercicio cooperativo entre los sujetos del estudio antropológico y el investigador, se trató de combinar diferentes elementos de experiencias locales y globales. Claramente, los resultados híbridos finales, en parte fueron conformados por estructuras de poder a su vez determinadas por procesos históricos que se extendían más allá de las vidas individuales de los mismos protagonistas. Esto no era algo fijo o predeterminado, sino dependiente de dinámicas y contextos cambiantes. En ese sentido, los proyectos antropológicos en general, 
y los proyectos de antropología compartida en particular, se deben ver más como procesos activados por condiciones subjetivas y objetivas en vez de como simples recetas metodológicas. Últimamente, procesos similares a la experiencia de colaboración descrita aquí muestran más bien espacios interculturales objetivos, donde se desarrollan la expresión subjetiva y los procesos generales de creación social.

A un nivel más teórico, estas prácticas se beneficiaron de la experiencia de varias décadas de comunicación alternativa dentro y fuera de nuestro continente que miraban a los grupos indígenas, populares y marginales, ya no como audiencias de consumo pasivo, sino como grupos con capacidad de reelaboración creativa de mensajes. ${ }^{19}$ Además, se nutrieron de diferentes corrientes antropológicas y sus variantes revisionistas y posmodernas, particularmente en el campo de las antropologías visual, aplicada y política, mismas que han facilitado una construcción más polifónica de los textos antropológicos. Estas “aperturas" indudablemente han cambiado las formas en las que la antropología en general y la antropología visual en particular se practican, posibilitando la concepción de formas novedosas de interacción con los sujetos en el campo y también formas más experimentales de hacer etnografía. Indudablemente, tales percepciones han facilitado el cuestionamiento y en algunos casos la superación de un bien establecido pensamiento antropológico binario, que tiende a dividir a las sociedades en categorías tales como primitivo/ civilizado, tradicional/moderno, yo/otro, observador/ observado. ${ }^{20}$ La producción de textos etnográficos utilizando cámaras por los sujetos antropológicos puede ser vista como una oportunidad de desafiar tales dicotomías (Harvey, 1993: 167).

En este sentido, experiencias alternativas de medios de comunicación "micro" pueden ofrecer nuevas formas de entender cómo las comunidades indígenas reciben, rechazan, recrean y transforman los mensajes mediáticos de masas, a la vez que dan pistas sobre cómo tales prácticas articulan la dimensión cotidiana con la global, el ámbito privado con lo público y la esfera familiar con el poder. ${ }^{21}$ Edificando sobre tales experiencias, es posible imaginar formas novedosas de colaborar con grupos indígenas en proyectos compartidos desde una perspectiva más horizontal. Estos esfuerzos colaborativos deben dejar lo más claro posible, lo que cada involucrado está tratando de lograr para, basados en ese entendimiento, diseñar y negociar los niveles de participación y resultados de todo el proceso de producción. Una mejor aprehensión del "punto de vista del nativo" sobre la base de tal colaboración puede llevar a una mayor cercanía en la creación de productos compartidos que a la vez tengan una circulación y consumo más balanceado. Al compartir de manera responsable el conocimiento etnográfico con las comunidades estudiadas, los antropólogos visuales podrán estar mejor preparados para responder a la “...cuestión teórica constantemente discutida en los experimentos de comunicación alternativa: la relación entre la acción yla representación" (Reyes Mata, 1986:207).

Sin embargo, con estas consideraciones, la capacidad de que una iniciativa sea "compartida" y "en colaboración" depende más de la posibilidad de los proyectos, de establecer áreas comunes donde los involucrados puedan negociar, combinar y materializar diferentes intereses y formas distintas. El éxito o fracaso de tales prácticas comunes tienen que ver, por ello, con la capacidad de articular procesos y resultados que conlleven sentido para sus participantes. Es decir, éstos deben ser proyectos que busquen desarrollar una práctica antropológica con resultados y beneficios múltiples, donde diferentes iniciativas se puedan amarrar al interior de un mismo proceso colectivo. Sin embargo, también hay que ser concientes de que a pesar de las buenas intenciones, la construcción colectiva de un texto con características multivocales, debido a las relaciones de poder inevitablemente presentes, puede con facilidad disfrazar nuevas y sofisticadas formas de apropiación 
cultural donde la intención de "compartir" sea sólo una ilusión. De esta manera, es importante establecer en la medida de lo posible cómo los sujetos y subjetividades se transforman en objetos y son objetivizados al interior de la práctica antropológica. Quizá lo que está en juego en cualquier encuentro antropológico que busca procesos "compartidos" — y por extensión prácticas "aplicadas" o "políticas" — es la forma en que el poder de actuar y proponer se establece, y cómo los resultados se distribuyen dentro de sus diferentes participantes. En estos tiempos, empresas antropológicas compartidas deberían proveer espacios para el autodescubrimiento y la construcción creativa de la propia identidad. Sobre todo deberían de ser procesos en los que tanto el antropólogo como los sujetos de estudio puedan mutuamente potenciar lo mejor de sus energías. Como afirmara Paulo Freire (1985), la investigación debería representar una oportunidad de involucrarse, no de invadir.

\section{Notas}

${ }^{1}$ Este escrito se basa en la tesis de doctorado del autor titulada "Video Indígena, Memoria y Antropología Compartida en la Posguerra de Guatemala: Experiencias de Filmación Colaborativa entre los Q'eqchi' de Alta Verapaz", presentada en la Universidad de Manchester en febrero de 2000. El autor también ha participado en proyectos de video comunitario en Guatemala y México, y por algunos años dio clases en el programa de maestría de antropología visual en el Goldsmiths College, Universidad de Londres, antes de incorporarse a la UAEM, México.

${ }^{2}$ Con el apoyo de la comunidad internacional, el Estado guatemalteco se encontraba negociando un tratado de paz con la guerrilla organizada en la Unidad Revolucionaria Nacional Guatemalteca (URNG), el que tiempo después finalizó con 36 años de conflicto armado en el que según la ONU unas 200000 personas, en su mayoría indígenas, perecieron.

3 Véase Asad, 1986. Abu-Lughod observa que: "Incluso intentos de reconfigurar a los informantes como consultores y 'dejarlos hablar' en textos dialógicos o polivocales - descolonización a nivel del texto- deja intacta la configuración básica del poder global en el que se basa la antropología, al estar vinculada a otras instituciones mundiales" (citado en Nordstrom, 1997: 30).

${ }^{4}$ Las iglesias protestantes incluso iniciaron sus políticas desarrollistas y de educación aplicada a finales del siglo XIX, cuando la llamada Revolución Liberal de 1871 vio en ellas una alternativa al conservadurismo de la iglesia católica de entonces y un buen ejemplo de lo que se consideraba una ética favorable hacia los ideales de modernización y progreso (véase Garrard Burnett, 1994).

${ }^{5}$ Por algunos años de la década de 1990, Centroamérica se convirtió en el mayor recipiente de ayuda internacional en el mundo. En 1994, por ejemplo, cerca de 170 millones de Ecus (precursor de la moneda Euro) fueron enviados a la región por la Unión Europea, la que a su vez se convirtió en el mayor donante multilateral en la región. Guatemala fue un caso ejemplar del planteamiento europeo hacia Latinoamérica, que se enfocaba crecientemente hacia procesos de democratización, el respeto a los derechos humanos y el buen gobierno (véase cIIr, 1998).

${ }^{6}$ La rama benedictina de la iglesia, con sede central en Blue Cloud Abbey en Dakota, llegó a Alta Verapaz en 1964 siguiendo los lineamientos del Papa de enviar 10 por ciento de sus misioneros a Latinoamérica. Sus religiosos ya habían establecido una larga relación de trabajo con grupos amerindios norteamericanos como los sioux, dakotas y metis (una mezcla de chippawa y franceses) con el fin de "americanizar poco a poco a la gente para facilitar su integración a una sociedad más global” (panfleto benedictino acerca del origen de la orden, $\mathrm{s} / \mathrm{f}$ ).

${ }^{7}$ Véase Melgoza (2005: 88, 89).

${ }^{8}$ Véase también Turner, 1991, 1992; Moore, 1992; Worth y Adair, 1997; McDougall, 1994; Chalfen, 1992; y McLellan, 1987.

${ }^{9}$ Con anterioridad, el poder dentro de las comunidades se adquiría normalmente con edad, sin embargo, al asociarse con instituciones poderosas (primero con la iglesia católica y después con el ejército) los jóvenes lograron adquirir antes de tiempo posiciones de autoridad al interior de la comunidad. Sin darme cuenta, según lo entendí después, mi propuesta estaba amenazando su papel tan prestigioso como intermediarios de modernidad, mientras que al mismo tiempo daba poder nuevamente a la autoridad de los ancianos, que en buena medida venía de su conocimiento "tradicional". ${ }^{10}$ Véase Flores, 2000. 
${ }^{11}$ Quisiera agradecer a Sergio Navarrete por sus iluminadores comentarios en relación con este punto.

12 Se puede observar una similitud importante con la experiencia de video entre los kayapó de Brasil; según Turner, para este grupo amazónico "el acto de filmar con una cámara de video puede volverse un mediador todavía más importante en sus relaciones con la cultura dominante de Occidente que el video-documento en sí mismo" (1992: 7).

${ }^{13}$ Véase Barbash y Taylor (1997: 17).

${ }^{14} \mathrm{El}$ cine observacional ha sido privilegiado al interior de la antropología debido a que trata de transmitir a la audiencia un recuento de la actividad filmada lo más fielmente posible, por lo tanto busca una menor intervención del cineasta/ antropólogo en el sentido de agregar música externa, efectos especiales, comentarios, etcétera.

${ }^{15}$ Esto en sí mismo me generó algunos cuestionamientos éticos y metodológicos alineados con las preguntas de David MacDougall (1994: 31), quien se cuestiona: "si las etnografías ahora incorporan otras voces, ¿qué independencia textual tienen estas voces en realidad? En términos absolutos, todos los textos utilizados de esta forma se encuentran subordinados al texto del autor".

${ }^{16}$ Véase Flores, 1999.

${ }^{17}$ Qa Loq L aj Iyajganó el premio continental "L anza de Amaru de la Nacionalidad Awna para la categoría cosmovisión” durante el Tercer Festival de Cine y Video de las Primeras Naciones de Abya-Yala, que se llevó a cabo en Ecuador, julio de 1999.

${ }^{18}$ Esta primera experiencia, eventualmente dio paso a la producción de otra película etnográfica en una comunidad diferente, meses después, llamada Rub'el Kurus, «Bajo la Cruz», sobre la violencia sufrida en varias comunidades q'eqchi' durante la guerra. Esta nueva producción resolvió varios problemas surgidos durante la filmación de Nuestra Sagrada Semilla, al mismo tiempo que el nuevo contexto generó una nueva serie de preguntas metodológicas. Rub'el Kurus fue presentado más tarde en el VI Festival Internacional de Cine Etnográfico que se llevó a cabo en Goldsmiths College, Universidad de Londres, en septiembre de 1999. En esa ocasión, el Royal Anthropological Institute, la institución antropológica más antigua del mundo, generosamente invitó al camarógrafo y editor q’eqchi' Mainor Pacay para que llegara a discutir conmigo este proyecto compartido desde nuestras diferentes perspectivas (cf. Flores, 1999 y 2000).

${ }^{19}$ Véase Winocur, 2002; y García Canclini, 1995.

${ }^{20}$ Véase Russell (1999: 19).

${ }^{21}$ Véase Schwartz y Jaramillo (1986: 68), y Winocur (2002: 33).

\section{Bibliografía}

Asad, Talal, 1986, "The Concept of Cultural Translation in British Social Anthropology", en J. Clifford y G. Marcus (eds.), Writing Culture: The Poetics and Politics of Ethnography, University of California Press, Berkeley, pp. 141-164.

Barbash, Ilisa y Lucien Taylor, 1997, Cross-Cultural Filmmaking: A Handbooke for Making Documentary and Ethnographic Films and Videos, University of California Press, Berkeley.

Capriles, Oswaldo, 1981, "Venezuela: ¿Política de comunicación o comunicación alternativa?”, en Máximo Simpson Gringberg (comp.), Comunicación Alternativa y Cambio Social: I. América Latina, Universidad Nacional Autónoma de México, pp. 149-166.

Carelli, Vincent, 1989, "Video in the Villages: Utilization of Video-Tapes as an Instrument of Ethnic Affirmation Among Brazilian Indians", in CVA (Commission on Visual Anthropology) Newsletter, pp. 10-15.

Chalfen, Richard, 1992, "Picturing culture through indigenous imagery: a telling story", en Ian Crawford y David Turton (eds.), Film as Ethnography, Manchester University Press, Manchester, pp. 222-241.

CIIR (Catholic Institute for International Relations), 1998, Europe and the Guatemalan Peace Process: An Analysis of European Union Policy towards Guatemala, 1986-97, CIIR, Londres.

Clifford, James y George E. Marcus (eds.), 1986, Writing Culture: The Poetics and Politics of Ethnography, University of California Press, Berkeley.

Clifford, James, 1986, "Partial Truths", en J.Clifford y G. Marcus (eds.), Writing Culture: The poetics and Politics of Ethnography, University of California Press, Berkeley, pp. 1-26.

Flores, Carlos, 1999, "Shared Anthropology in Guatemala", en Anthropology Today, Vol. 15, Núm. 1, Londres, pp. 19-20.

—, 2000, "Indigenous Video, Memory and Shared Anthropology in Post-War Guatemala: Collaborative Film-making experiences among the Q'eqchi' of Alta Verapaz", tesis de doctorado, Departamento de Antropología, Universidad de Manchester, Inglaterra.

Freire, Paulo, 1985, Pedagogy of the Oppressed, Pelican Books, Londres.

Gallois, Dominique T. y Vincent Carelli, 1995, “Vídeo e diálogo cultural-Experiências do Projeto Vídeo nas Aldeias", en Cornelia Eckert y Nuno Godolphim (eds.), Horizontes Antropológicos-Antropología Visual, Publicación del 
Programa de Posgrado en Antropología Social de la Universidad Federal de Río Grande del Sur, Brasil.

García Canclini, Néstor, 1995, Consumidores y Ciudadanos, Editorial Grijalbo, México.

Garrard Burnett, Virginia, 1994, "God and Revolution: Protestant Missions in Revolutionary Guatemala, 19441954”, en John A. Britton (ed.), Molding the Hearts and Minds: Education, Communications, and Social Change in Latin America, Jaguar Books on Latin America, Wilmington, Delaware, pp. 127-145.

Ginsburg, Faye, 1997, "From Little Things, Big'Things Grow: Indigenous Media and Cultural Activism”, en Richard Fox y Orin Starn (eds.), Between Resistance and Revolution: Cultural Politics and Social Protest, Rutgers University Press, Brunswick, pp. 118-144.

Gómez Mont, Carmen, 2002, “El Desafío de Internet ante la construcción de los usos sociales. El caso de las comunidades indígenas mexicanas", ponencia presentada en el Coloquio Panamericano: Industrias Culturales y Diálogo de las Civilizaciones en las Américas, 22-25 de abril, Montreal, Canadá. Documento electrónico accesible en: http:// www.er.uqam.ca/nobel/gricis/actes/panam/ Gomez.pdf.

Harvey, Penny, 1993, "Ethnographic Film and the Politics of Difference: A Review of Film Festivals", en Visual Anthropology Review, Vol. 9, Num. 1, pp. 164-176.

Henley, Paul, 1998, "Film-making and Ethnographic Research", en Jon Prosser (ed.), Image-based Research: A Sourcebook, for Qualitative Researcher, Falmer Press, Londres.

Kaplún, Mario, 1981, “Uruguay: Participación, Praxis, Problema. La experiencia del casete-foro», en Máximo Simpson Gringberg (comp.), Comunicación Alternativa y Cambio Social: I. América Latina, Universidad Nacional Autónoma de México, pp. 215-236.

Kuper, Adam, 1986, "Culture, Identity and the Project of a Cosmopolitan Anthropology", en Man (N.S.) 29, pp. 537-554.

MacDougall, David 1994, "Whose Story Is It?”, en Lucien Taylor (ed.), Visualizing Theory: Selected Essays From V.A.R. 1990-1994, Routledge, London, pp. 27-36.

McLellan, Ian, 1987, "Video and Narrowcasting: TV for and by ordinary people", en Media in Education and Development, 20 (4), pp. 144-149.

Marcus, George E., 1986, "Contemporary Problems of Ethnography in the Modern World System, en James Clifford y George E. Marcus (eds.), Writing Culture: The
Poetics and Politics of Ethnography, University of California Press, Berkeley, pp. 165-193.

Melgoza García, Verónica, 2005, «Comunicación Indígena en Chiapas. Del Congreso Indígena de 1974 a los comunicadores de Melel Xojobal de 2004. Un estudio de caso», Tesis de Maestría, Centro de Investigaciones y Estudios Superiores en Antropología Social (CIESASSureste), San Cristóbal de Las Casas, Chiapas, México.

Moore, Rachel, 1994, "Marketing Alterity", en Lucien Taylor (ed.) Visualizing Theory: Selected Essays from V.A.R. 1990 1994, Routledge, London, pp. 126-139.

Nordstrom, Carolyn, 1997, A Different Kind of War Story, University of Pennsylvania Press, Philadelphia.

Reyes Mata, Fernando, 1986, "Alternative Communication: Solidarity and Development in the Face of Transnational Expansion", en R. Atwood y E. G. McAnany (eds.), Communication and Latin American Society: Trends in Critical Research, 1960-1985, The University of Wisconsin Press, Wisconsin, pp. 165-189.

Russell, Catherine, 1999, Experimental Ethnography: The Work of Film in the Age of Video, Duke University Press, Durham y Londres.

Selser, Gregorio, 1981, "Brasil: El fenómeno de la 'Imprenta Nanica"”, en Máximo Simpson Gringberg (comp.), Comunicación Alternativa y Cambio Social: I. América Latina, Universidad Nacional Autónoma de México, pp. 295-317.

Stoller, Paul, 1992, The Cinematic Griot: The Ethnography of Jean Rouch, The University of Chicago Press, Chicago y Londres.

Schwartz, Cristina and Jaramillo, Oscar, 1986, "Hispanic American Critical Communication Research in its Historical Context", en R. Atwood and E.G. McAnany (eds.), Communication and Latin American Society: Trends in Critical Research, 1960-1985, The University of Wisconsin Press, Wisconsin, pp. 48-75.

Turner, Terence, 1992, "Defiant Images: The Kayapo appropriation of video", en Anthropology Today, Vol. 8, Num. 6, pp. 5-16.

—, 1991, "The Social Dynamics of Video Media in an Indigenous Society: The Cultural Meaning and the Personal Politics of Video-making in Kayapo Communities", en Visual Anthropology Review, Vol. 7, Num. 2, pp. 68-76.

Winocur, Rosalía, 2002, Ciudadanos Mediáticos: La construcción de lo público en la radio, Editorial Gedisa, Barcelona.

Worth, Sol and Adair, John, 1972, Through Navajo Eyes: An exploration in film, communication and Anthropology, Indiana University Press: Bloomington. 